\title{
Statin inhibits interferon- $\gamma$-induced expression of intercellular adhesion molecule-1 (ICAM-1) in vascular endothelial and smooth muscle cells
}

\author{
Hyo Kyun Chung ${ }^{1}$, In Kyu Lee ${ }^{2}$, Hyokyung \\ Kang $^{2}$, Jae Mi Suh ${ }^{1}$, Ho Kim ${ }^{1}$, Ki Cheol Park ${ }^{1}$, \\ Dong Wook Kim ${ }^{1}$, Young Kun Kim¹, Heung \\ $\mathrm{Kyu} \mathrm{Ro}^{1}$ and Minho Shong ${ }^{1,3}$ \\ 'Department of Internal Medicine \\ School of Medicine, Chungnam National University \\ Daejon 301-721, Korea \\ ${ }^{2}$ Department of Internal Medicine \\ School of Medicine, Kyemyung University \\ Daegu, Korea \\ ${ }^{3}$ Corresponding author: Tel, 82-42-220-7161; \\ Fax, 82-42-257-5753; E-mail, minhos@cnu.ac.kr
}

Accepted 9 December 2002

Abbreviations: ERK1, extracellular signal-regulated kinase; GAS, IFN- $\gamma$ activated site; HMG-CoA, 3-hydroxy-3-methylglutaryl coenzyme A; ICAM-1, Intercellular adhesion molecule-1; IFN- $\gamma$, interferon- $\gamma$; SMC, smooth muscle cell; STAT, signal transducers and activators of transcription; TNF- $\alpha$, tumor necrosis factor- $\alpha$

\begin{abstract}
Inhibitors of 3-hydroxy-3-methylglutaryl coenzyme A (HMG-CoA) reductase, known as statins, are widely used for primary and secondary prevention of coronary artery atherosclerosis. Pathogenesis of atherosclerosis is multistep processes where transendothelial migration of various leukocytes including monocytes is a crucial step. Interferon- $\gamma$ (IFN- $\gamma$ ) contributes in this process by activating macrophages and T-lymphocytes, and by inducing adhesion molecules in vascular endothelial and smooth muscle cells. In this study we investigated the expression of intercellular cell adhesion molecule-1 (ICAM-1) in transformed endothelial cell line ECV304 cells as influenced by lovastatin, tumor necrosis factor- $\alpha$ (TNF- $\alpha$ ) and IFN- $\gamma$. Results show that lovastatin suppresses expression of ICAM-1 by inhibiting the IFN- $\gamma$-induced extracellular signalregulated kinase (ERK) p44/p42-STAT1 signaling pathway. In cells treated with lovastatin and IFN- $\gamma$, ICAM-1 was expressed at a lower level than in cells treated with IFN- $\gamma$ alone. However, lovastatin does not reduce TNF- $\alpha$ induced expression of
\end{abstract}

ICAM-1. A similar result was observed in cells treated with the MEKK inhibitor PD98059 and IFN- $\gamma$. Cis-acting DNA sequence elements were identified in the 5'-flanking region of the ICAM-1 promoter that mediate inhibition by lovastatin; these sequences map to the IFN- $\gamma$ activated site which also binds the STAT1 homodimer. However, lovastatin did not inhibit IFN- - -mediated induction of the Y701 phosphorylated form of STAT1. But lovastatin does inhibit the IFN- $\gamma$-mediated phosphorylation of ERK1/ERK2 (T202/Y204) and S727 phosphorylation of STAT1. TNF- $\alpha$ does not induce phosphorylation of ERK1/ERK2 and S727 in ECV304 and smooth muscle cells. The results provide the evidences that statins may have beneficial effects by inhibiting IFN- $\gamma$ action in atherosclerotic process

Keywords: arteriosclerosis; endothelium, vascular; interferon type II; mitogen-activated protein kinases; p42 MAP kinase

\section{Introduction}

Inhibitors of 3-hydroxy-3-methylglutaryl coenzyme A (HMG-CoA) reductase are widely used for primary and secondary prevention of coronary artery atherosclerosis (Pedersen, 1999; Maron et al., 2000; Gotto et al., 2001). This group of drugs is familiarly known as "statins" and their common mechanism of action is inhibition of cholesterol synthesis in the liver by blocking the conversion of HMG-CoA to mevalonate. HMG-CoA reductase catalyzes the rate-limiting step in the mevalonate pathway; therefore, treatment with statins can lower plasma low density lipoprotein (LDL) on a long-term basis. Recent studies indicate that HMG-CoA reductase inhibitors affect other cellular processes including G1/S progression (Naderi et al., 1999; Kim et al., 2000), proliferation and apoptosis (Guijarro et al., 1998; Kureishi et al., 2000). HMGCoA reductase inhibitors suppress the synthesis of isoprenoid intermediates of cholesterol metabolism such as geranylgeranylpyrophosphate and farnesylpyrophosphate, which reduces farnesylation and geranylgeranylation of many proteins, including GTP-binding proteins Ras, Rac and Cdc42 (Laufs et al., 2000). These unmodified GTP-binding proteins are poorly 
inserted into the plasma membrane and normal signaling activities are inhibited. Downstream signaling by small GTP-binding proteins involves several effector pathways, and effector molecules including Raf proteins and members of the RalGDS family (i.e., phosphatidylinositol 3-kinase (PI3K), MEKK, Rin1, AF$6)$. The first Ras effector, Raf, phosphorylates mitogen-activated protein kinase (MAPK), extracellular signal-regulated kinase (ERK), which in turn activates the p42 and p44 MAPKJERK kinases (Takai et al., 2001). Recent studies indicate that statins effectively repress the IFN- $\gamma$-mediated induction of MHC class II proteins by inhibiting activity of the CIITA promoter IV (Kwak et al., 2000).

Atherosclerosis is an inflammatory disease characterized by lesions on arterial walls. Within these lesions, endothelial and smooth muscle cell (SMC) express an increased level of leukocyte adhesion molecules on their surface including a high level of intercellular adhesion molecule-1 (ICAM-1) (Ross, 1990). ICAM-1 is largely responsible for recruiting immune cells to atherosclerotic lesions and for activating lymphocytes in lesions (Ross, 1990; Collins et al., 2000). ICAM-1 expression is mainly regulated by transcription factors that bind to enhancer elements in the promoter of the ICAM-1 gene; these include NF-kB, AP1, GAS and SP1 (Stratowa et al., 1995).

Expression of ICAM-1 depends on an IFN- $\gamma$-dependent signaling pathway in which the latent transcription factor signal transducers and activators of transcription 1 (STAT1) is a critical intermediate (Chung et al., 2000). The ICAM-1 promoter has a palindromic GAS element, which is a cis-element required for STAT-dependent transcription, located 115 bp upstream of the translation initiation site. ICAM-1 expression has been studied in a STAT1-deficient cell line (Walter et al., 1997). Transfection of a plasmid expressing wild type STAT1 restored IFN- $\gamma$-dependent expression of the endogenous ICAM-1 gene or cotransfected constructs containing the ICAM-1 promoter. However, when STAT1 mutants with substitutions at tyrosine 701 (Jak phosphorylation site), or serine 727 (MAP kinase phosphorylation site) were expressed in the STAT1-deficient cell line, ICAM-1 promoter activity was low. These results strongly suggest that the STAT1-dependent signaling pathway plays a major role in IFN- $\gamma$-induced expression of ICAM-1 (Walter et al., 1997).

IFN- $\gamma$ contributes to the pathogenesis of atherosclerosis by activating macrophages and T-lymphocytes, and by inducing expression of cell adhesion molecules in atherosclerotic lesions (Ross, 1993). In vivo studies show that artherosclerosis is reduced in mice with an IFN- $\gamma$ knockout or a double knockout in apoE and IFN- $\gamma$ (Gupta et al., 1997; Nagano et al., 1997). IFN- $\gamma$ induces expression of early response genes by activating JAK1, JAK2 and STAT1 (Darnell, 1997). IFN- $\gamma$ induces phosphorylation of tyrosine 701 of STAT1 by JAK1 and JAK2, and phosphorylation of serine 727 by Raf-1/MAP kinases (Decker et al., 2000). Phosphorylation of serine 727 is required for maximal transcriptional activity of STAT1 (Darnell, 1997; Decker et al., 2000).

This study shows that lovastatin suppresses IFN- $\gamma$ induced expression of ICAM1. Lovastatin modulates MAP kinase activity which suppresses IFN- - -induced phosphorylation of serine 727 in STAT1. Thus, lovastatin and possibly other statins may have beneficial effects as therapeutics for artherosclerosis by inhibiting IFN- $\gamma$-induced expression of adhesion molecules.

\section{Materials and Methods}

\section{Materials}

Cell culture media, fetal bovine serum (FBS), glutamine, and penicillin/streptomycin were purchased from Bio-Whittaker (Walkersville, MD). Cell culture plates were from Falcon (Falcon Division, Becton Dickinson Laboratories, Rutherford, NJ). Lovastatin was a gift of Parke-Davis Pharmaceuticals Research (Ann Arbor, MI). Dowex AG 50WX-8 cation exchange resin (100200 mesh) was from Bio-Rad Laboratories (Hercules, CA). X-OMAT S X-ray film was from Eastman Kodak (Rochester, NY). Human recombinant IFN- $\gamma$ and human TNF- $\alpha$ was from Gibco Laboratories Life Technologies (Grand Island, NY) and Pharmingen (San Diego, CA $)$, respectively. $\left[\alpha-{ }^{32} \mathrm{P}\right] \mathrm{dCTP}(3000 \mathrm{Ci} / \mathrm{mmol})$ was from DuPont-New England Nuclear (Boston, MA). The source of all other materials was Sigma Chemical (St. Louis, MO) unless otherwise noted.

\section{Cell culture and treatments}

Transformed endothelial cell line ECV304 cells were grown in medium 199 (Hepes modification) containing $10 \%(\mathrm{v} / \mathrm{v}) \mathrm{FBS}$, and passaged when confluent using $0.05 \%(w / v)$ trypsin, $0.02 \%$ (w/v) EDTA. Human primary vascular smooth muscle cell cultures were begun from the medial smooth muscle cell layers of the internal mammary artery. The internal mammary artery was obtained during the operation of coronary artery bypass graft followed by direct mechanical stripping of transverse layers of medial smooth muscle including endothelium. Strips $(1 \mathrm{~mm})$ of tissue were then incubated in $4 \mathrm{ml}$ per artery of $0.25 \%$ trypsin for $10 \mathrm{~min}$ at $37^{\circ} \mathrm{C}$. Endothelial cells were removed by incubation of strips with $5 \mathrm{ml}$ of collagenase $(2 \mathrm{mg} / \mathrm{ml})$ in $\mathrm{M} 199$ medium for $60 \mathrm{~min}$ at $37^{\circ} \mathrm{C}$ in a $\mathrm{CO}_{2}$ incubator. Smooth muscle cells were dispersed by incubation with $2 \mathrm{ml}$ of elastase $(0.25$ 
$\mathrm{mg} / \mathrm{ml}$ ) for $60 \mathrm{~min}$ at $37^{\circ} \mathrm{C}$, followed by addition of $5 \mathrm{ml}$ of collagenase and DNAase I to a final concentration of $2.5 \mu \mathrm{g} / \mathrm{ml}$ for a further $1-2 \mathrm{~h}$. Smooth muscle cells were resuspended in DMEM containing $10 \% \mathrm{fe}-$ tal calf serum, $2 \mathrm{mM}$ glutamine, 100 units $/ \mathrm{ml}$ penicillin, $100 \mu \mathrm{g} / \mathrm{ml}$ streptomycin, and $0.25 \mu \mathrm{g} / \mathrm{ml}$ fungizone. Cells were counted by trypan blue exclusion and routinely showed $>95 \%$ viability. Cells were seeded at $1 \times 10^{4} / \mathrm{cm}^{2}$ and allowed to attach, and the medium was changed after $48 \mathrm{~h}$. Cells were occasionally checked for endothelial cells and were routinely negative when stained for von Willebrand antigen. Cells were split 1:3 during passaging and were used at passage number 2 unless otherwise stated.

\section{Cell viability}

Cellular toxicity of statins was tested by trypan blue exclusion. Furthermore, potential induction of apoptosis was studied by DNA fragmentation analysis in agarose gels and by analysis of the cell cycle distribution assessed by flow cytometry in the presence of propidium iodide. No significant changes in either of these parameters were observed with lovastatin at the concentration range used in this work for $24 \mathrm{~h}$.

\section{Cell surface ICAM-1 staining and flow cytometric analysis}

ECV 304 cells were incubated with recombinant IFN- $\gamma$ $(10 \mathrm{ng} / \mathrm{ml})$ or TNF- $\alpha(20 \mathrm{ng} / \mathrm{ml})$ in the presence or absence of lovastatin $(10 \mu \mathrm{M})$ at $37^{\circ} \mathrm{C}$ and $5 \% \mathrm{CO}_{2}$ for the indicated amount of time. Cells were washed three times in an isotonic cold PBS buffer (supplemented with $0.5 \% \mathrm{BSA}$ ) after trypsin/EDTA treatment and then incubated for $30 \mathrm{~min}$ at $4^{\circ} \mathrm{C}$ with monoclonal anti-human ICAM-1 fluorescein (CD54) (R\&D systems, Minneapolis, MN). Following this incubation, unreacted anti-ICAM-1 reagents were removed by washing and the cells were resuspended in $200 \mu$ of PBS buffer for final flow cytometric analysis. Cells were analyzed using a Beckton Dickinson FACScan.

\section{RNA isolation and Northern analysis}

Total cellular RNA was isolated by standard procedures and Northern analysis was performed as described (Chung et al., 2000). Final washes were carried out at $65^{\circ} \mathrm{C}$ in $1 \times \operatorname{SSPE}(150 \mathrm{mM} \mathrm{NaCl}, 10 \mathrm{mM}$ $\mathrm{NaH}_{2} \mathrm{PO}$, $1 \mathrm{mM}$ EDTA, pH 7.4). The human ICAM-1 probes were the purified insert fragments after restriction with Sal1 and Pst1 from the expression vector pCD1.8 (Dr. T. A. Springer, Center for Blood Research, Harvard Medical School, Boston, MA). All probes were radiolabeled by a random priming protocol (Amersham Life Science, Arlington Heights, IL).

\section{Construction of promoter/luciferase chimeric plas- mids}

Chimeric expression constructs using fragments of pCAM-1822, containing 1,822 bp of the $5^{\prime}$-flanking region of the rat ICAM-1 gene, were made using high fidelity PCR (Wertheimer et al., 1992; An et al., 1997). Promoter segments were amplified with pfu polymerase using appropriate forward and reverse primers including a Bg/ll site (5'-end) and HindIII site ( $3^{\prime}$-end). Mutations of promoter sequences were generated by PCR using primers incorporating the mutated sequence. Amplified fragments were ligated into the pGL2-basic vector containing a luciferase reporter gene and the correct DNA sequence was confirmed by DNA sequencing analysis. The 5 '-deletion mutants included pCAM-431, pCAM-175, pCAM-175 GAS mut, and pCAM-95, containing the indicated fragment of the ICAM-1 promoter starting from the numbered nucleotide at the 5 '-end and extending to $+1 \mathrm{bp}$, the start of protein translation. All plasmid preparations were purified twice by $\mathrm{CsCl}$ gradient centrifugation.

\section{Transfection}

ECV304 cells were plated in 60-mm dishes at $60-80 \%$ confluency and transfected by lipofection using LipofectAmine Plus (Life Technologies) according to the manufacturer's instructions. For transfection, $2 \mu \mathrm{g}$ of pCAM-1822 or equivalent molar amounts of the deletion mutants or pGL2-basic (negative control) were used. To compare different transfections done the same day, the cells were additionally transfected with $20 \mathrm{ng}$ of pRL-TK (Promega, Madison, WI), which encodes a Renilla luciferase gene downstream of a minimal HSV-TK promoter. Following stimulation of transfected cells, both Renilla luciferase and luciferase were measured using the Dual Luciferase Assay System (Promega), and the Renilla values were used for normalization. To test the effect of cytokines and lovastatin, ECV 304 cells were exposed to various concentrations of IFN- $\gamma$, TNF- $\alpha$, lovastatin for $24 \mathrm{~h}$ before luciferase activity was measured.

\section{Western blot analysis}

The antibodies against MAP kinase p44/p42, STAT1 or phosphorylated forms of MAP kinase p44/p42, STAT1 (Y701, S727) were affinity purified rabbit polyclonal IgG (New England Biolabs, CA and Upstate Biotech Inc., Lake Placid, NY). For the Western blot, adherent ECV 304 and smooth muscle cells were stimulated with various agents for the indicated period of time at $37^{\circ} \mathrm{C}$. The treated cells were scraped, lysed by addition of SDS sample buffer [62.5 mM Tris- $\mathrm{HCl}$ (pH 6.8), 6\% (w/v) SDS, 30\% glycerol, 125 mM DTT, $0.03 \%(\mathrm{w} / \mathrm{v})$ bromophenol blue] and separated by 
$10 \%$ SDS-PAGE along with biotinylated molecular weight standards. The proteins were transferred to a nitrocellulose membrane by electrotransfer for $2 \mathrm{~h}$. After soaking the membrane in blocking buffer $(1 \times$ TBS, $0.1 \%$ Tween- 20 with $5 \%$ milk) the membrane was incubated with primary antibody overnight at $4^{\circ} \mathrm{C}$. Blots were developed using HRP-linked anti-rabbit secondary antibody and chemiluminescent detection system (Phototope-HRP Western Blot Detection Kit, New England Biolab, CA).

\section{Other assays}

Protein concentration was determined by Bradford's method (Bio-Rad, Hercules, CA) and used recrystallized bovine serum albumin as the standard.

\section{Statistical significance}

All experiments were repeated at least three times with different batches of cells. Values are the mean \pm SE of these experiments. Unless otherwise indicated, significance between experimental values was determined by two-way analysis of variance.

\section{Results}

\section{Lovastatin inhibits IFN- - -induced but not TNF- $\alpha$ - induced ICAM-1 protein expression}

The effects of IFN- $\gamma$, TNF- $\alpha$ and lovastatin on the cell surface expression of ICAM-1 were examined in transformed endothelial cell line ECV 304 cells. Cells were cultured in the presence of IFN- $\gamma$ or TNF- $\alpha$ with or without lovastatin for $24 \mathrm{~h}$. Cells were washed and stained with a fluorescein labeled-monoclonal anti-

$\mathbf{B}_{90}$
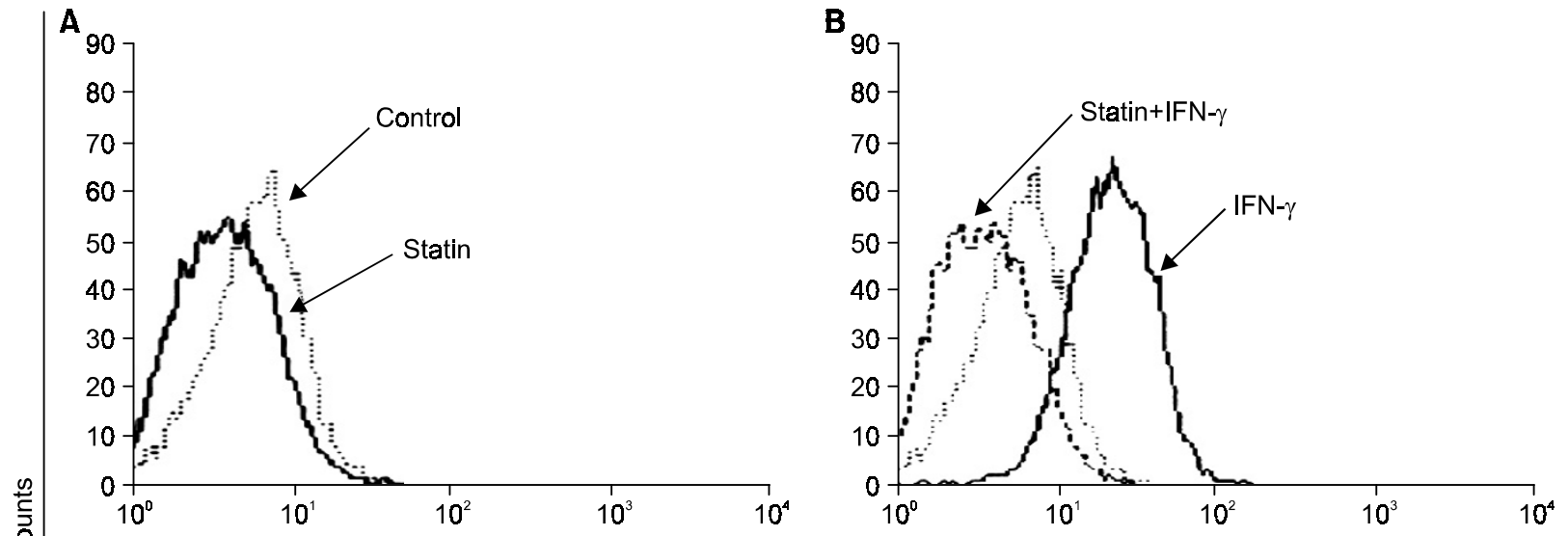

$D_{9}$

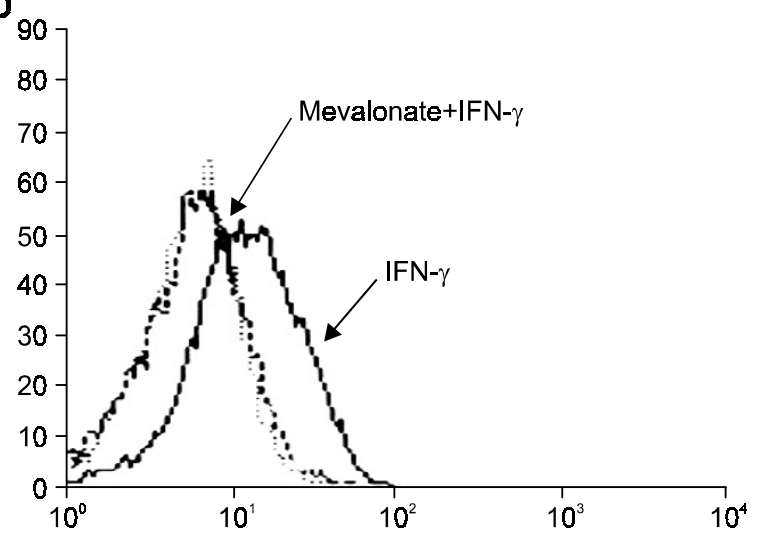

Anti-ICAM-1 Antibody

Figure 1. Flow cytometric analysis of statin effect on ICAM-1 upregulation in response to IFN- $\gamma$ and TNF- $\alpha$. ECV 304 cells were incubated with recombinant IFN- $\gamma(10 \mathrm{ng} / \mathrm{ml})$ or TNF- $\alpha(20 \mathrm{ng} / \mathrm{ml})$ in the presence or absence of lovastatin $(10 \mu \mathrm{M})$ at $37^{\circ} \mathrm{C}$ and $5 \% \mathrm{CO}_{2}$ for the indicated amount of time. Cells were washed three times in an isotonic cold PBS buffer (supplemented with $0.5 \%$ BSA) after trypsin/EDTA treatment and then incubated for $30 \mathrm{~min}$ at $4^{\circ} \mathrm{C}$ with monoclonal anti-human ICAM-1 fluorescein (CD54). Following this incubation unreacted anti-ICAM-1 reagents removed by washing and resuspended the cells in $200 \mu \mathrm{l}$ of PBS buffer for final flow cytometric analysis. Cells were analyzed using a Beckton Dickinson FACScan. 
human ICAM-1 (CD54) antibody and cell surface ICAM-1 was quantified using flow cytometry. Figure $1 \mathrm{~A}$ shows the basal constitutive level of expression of ICAM-1 on the surface of ECV 304 cells. Cells incubated in the presence of IFN- $\gamma(10 \mathrm{ng} / \mathrm{ml})$ for 24 $h$ have a significantly higher level of surface ICAM-1 (Figure 1B). ICAM-1 expression increased by $12 \mathrm{~h}$ in the presence of IFN- $\gamma$ and reached a maximum between 24 and $48 \mathrm{~h}$. The elevated ICAM-1 expression persisted for $72 \mathrm{~h}$ (data not shown). A dramatic increase in ICAM-1 expression was also evident after incubation in the presence of TNF- $\alpha(20 \mathrm{ng} / \mathrm{ml})$ for 24 $h$ (Figure 1C). Cells incubated in the presence of lovastatin and IFN- $\gamma$ express a similar level of cell surface ICAM-1 as control cells, suggesting that lovastatin inhibits the IFN- $\gamma$-dependent induction of ICAM1. In contrast, lovastatin does not inhibit TNF- $\alpha$-dependent induction of ICAM-1 (Figure $1 \mathrm{C}$ ). These results suggest that lovastatin may selectively inhibit certain steps of the IFN- $\gamma$ signaling pathway in endothelial cells.

\section{Lovastatin inhibits IFN- $\gamma$-induced but not TNF- $\alpha$ - induced ICAM-1 mRNA expression}

Cytokines regulate ICAM-1 expression at the tran-

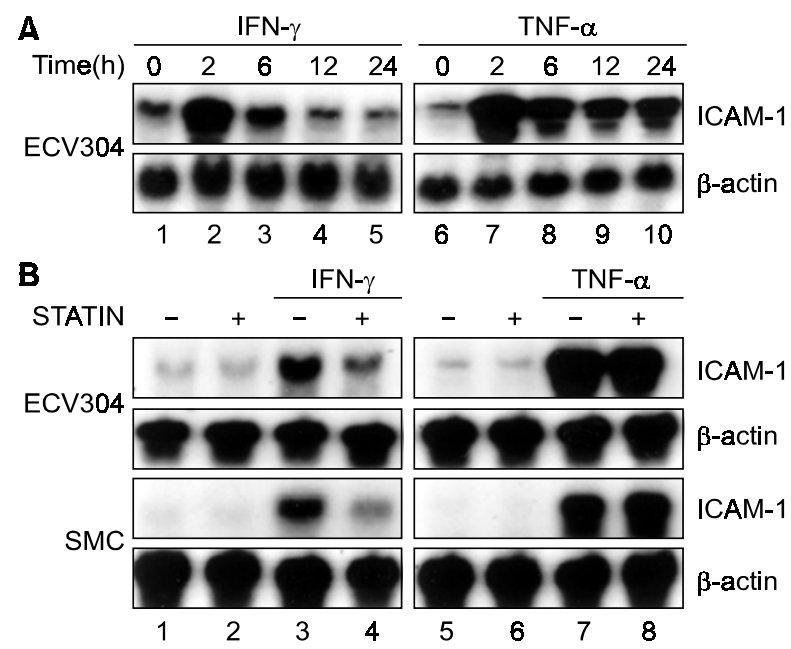

Figure 2. Effects of statin, IFN- $\gamma$ and TNF- $\alpha$ on ICAM-1 gene expression in ECV304 and vascular smooth muscle cells. (A) ECV304 cells were grown to near confluency in medium 199 containing $10 \%$ $(\mathrm{v} / \mathrm{V}) \mathrm{FBS}$. RNA was isolated after indicated treatment of IFN- $\gamma(10$ $\mathrm{ng} / \mathrm{ml})$ and TNF- $\alpha(20 \mathrm{ng} / \mathrm{ml})$ and analyzed by Northern blot using probes for ICAM- 1 and rat $\beta$-actin. The blots shown are representative Northern analyses from one experiment. Each lane contained $20 \mu \mathrm{g}$ total RNA. (B) After ECV304 and SMC cells were grown to near confluency, the cells were changed medium with or without lovastatin $(20 \mu \mathrm{M})$. The cells were stimulated with IFN- $\gamma(10 \mathrm{ng} / \mathrm{ml})$, and TNF- $\alpha$ $(20 \mathrm{ng} / \mathrm{ml})$ and then total RNA was isolated and subjected to Northern analyses using probes for human ICAM- 1 and $\beta$-actin as described in Materials and Methods. The results shown are Northern analyses from one experiment with $20 \mu \mathrm{g}$ RNA/lane. scriptional level. Thus, the effects of IFN- $\gamma$, TNF- $\alpha$ and lovastatin on transcription of the ICAM-1 gene were examined in ECV 304 endothelial cells. The basal constitutive level of ICAM-1 mRNA is shown in Figure $2 \mathrm{~A}$, lanes 1 and 6 and Figure 2B, lanes 1 and 5 . IFN- $\gamma(10 \mathrm{ng} / \mathrm{ml})$ rapidly and transiently induced ICAM1 mRNA, which reached a maximum within $2 \mathrm{~h}$ and returned to a near-basal level within $12 \mathrm{~h}$. TNF- $\alpha$ (20 $\mathrm{ng} / \mathrm{ml}$ ) also rapidly induced ICAM-1 mRNA within 2 $h$, but the elevated level persisted for $24 \mathrm{~h}$.

IFN- $\gamma$ induces ICAM-1 mRNA approximately 6-fold (Figure 2B, lane 3), and lovastatin inhibits induction of ICAM- 1 by IFN- $\gamma$ (Figure 2B, lane 3 vs. lane 4). However, lovastatin does not inhibit TNF- $\alpha$-mediated induction of ICAM-1 mRNA (Figure 2B, lane 7 vs. lane 8). Similar results were observed in smooth muscle cells (Figure 2B). Lovastatin inhibits IFN- $\gamma$-mediated induction of ICAM-1 mRNA, but it has no effect on TNF- $\alpha$-dependent induction of ICAM-1 mRNA in primary cultured smooth muscle cells.

Several studies show that INF- $\gamma$ and TNF- $\alpha$ activate MAP kinases p44/p42 (ERK1/ERK2) in several cell types (Dustin et al., 1986; Look et al., 1994). The role of MAP kinases p44/p42 in the IFN- $\gamma-$ and TNF- $\alpha$ dependent induction of ICAM-1 was determined using the MEKK inhibitor, PD98059. PD98059 significantly reduced ICAM-1 mRNA induction by IFN- $\gamma$ (Figure $3 A$, lane 3 vs. lane 4) but did not inhibit induction by TNF- $\alpha$ (Figure 3B, lane 3 vs. lane 4). These results suggest that MAP kinases are important for IFN- $\gamma$ signaling but not for TNF- $\alpha$ signaling.

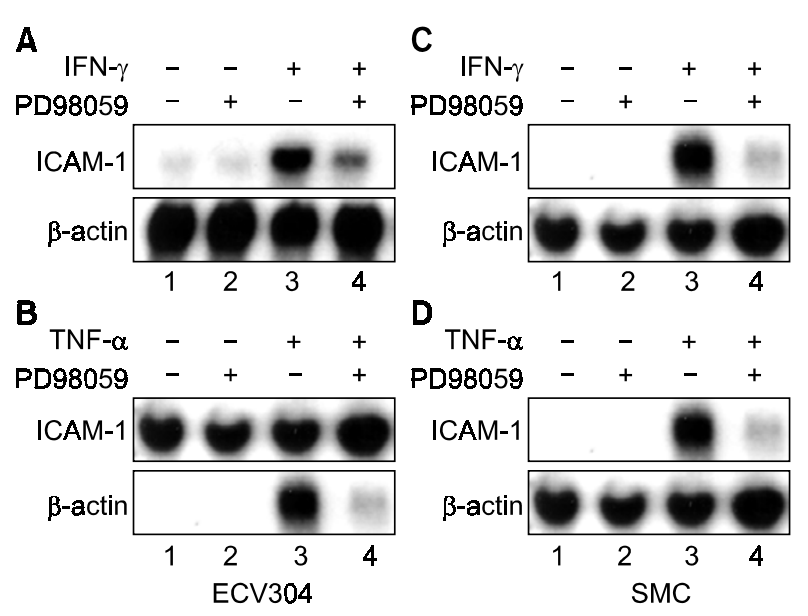

Figure 3. Effects of PD98059, IFN- $\gamma$ and TNF- $\alpha$ on ICAM-1 gene expression in ECV304 and SMC. ECV304 cells were grown to near confluency in medium 199 containing 10\% (v/v) FBS. RNA was isolated after indicated treatment of IFN- $\gamma(10 \mathrm{ng} / \mathrm{ml})$ and TNF- $\alpha(20$ $\mathrm{ng} / \mathrm{ml}$ ) with/without PD98059 and analyzed by Northern blot using probes for ICAM- 1 and rat $\beta$-actin. Each lane contained $20 \mu \mathrm{g}$ total RNA. 


\section{Regulation of the ICAM-1 promoter by lovastatin and/or IFN- $\gamma$}

The cis-acting regulatory elements in the ICAM-1 promoter were identified using serial deletion and mutation analyses of a reporter plasmid, pCAM-431, which has the firefly luciferase gene under control of the rat ICAM-1 promoter (Figure 4A). Several cisacting regulatory elements were identified including NF-kB (5'-ttggaaattc-3', -250 bp), GAS (-138 to 128 bp) and Sp1 (-112 to $108 \mathrm{bp})$. Reporter activity was examined to determine the function of these cis-acting regulatory sequences. IFN- $\gamma(10 \mathrm{ng} / \mathrm{ml})$ and TNF- $\alpha(20$ $\mathrm{ng} / \mathrm{ml}$ ) significantly increased reporter gene activity of pCAM-431 (Figure 4B). Lovastatin did not change the basal reporter activity of pCAM-431, but it significantly inhibited the IFN- $\gamma$-dependent increase in pCAM-431 reporter activity. As described for expression of the
ICAM-1 gene, lovastatin did not inhibit TNF- $\alpha$-dependent induction of PCAM-431 reporter activity (Figure 4B). These results are consistent with the observation that lovastatin differentially inhibits IFN- $\gamma$ and TNF- $\alpha$-dependent expression of ICAM-1.

Deletions were made in the ICAM-1 promoter region and the cis-acting element that confers responsiveness to lovastatin was mapped using luciferase reporter constructs. IFN- $\gamma$ increases the activity of the reporter construct with the full-length ICAM promoter (pCAM-1822) and of 5'-deletion mutants with 829, 431 or $175 \mathrm{bp}$ of the promoter (pCAM-829, pCAM-431, or pCAM-175, respectively; Figure $4 \mathrm{C}$ and data not shown). However, reporter construct pCAM-97 and control chimeric vector, pGL2-basic were not responsive to IFN- $\gamma$ (Figure 4C). Thus, IFN- $\gamma$-mediated regulation of transcription requires DNA sequence elements between -175 and $-97 \mathrm{bp}$ from the start of
A

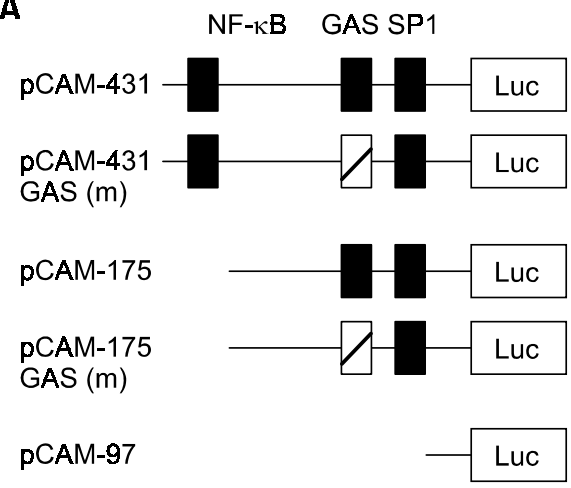

B

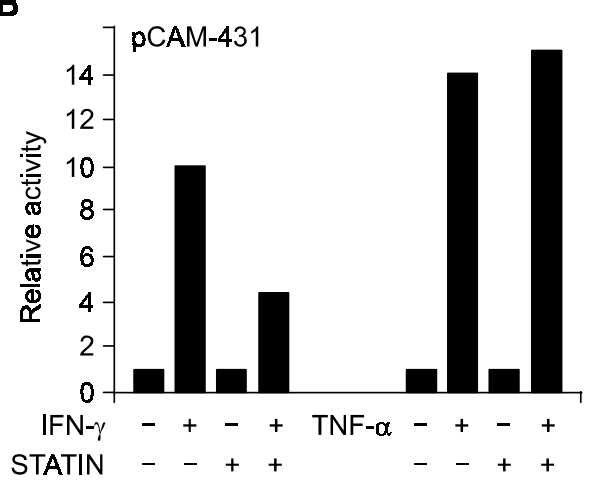

C

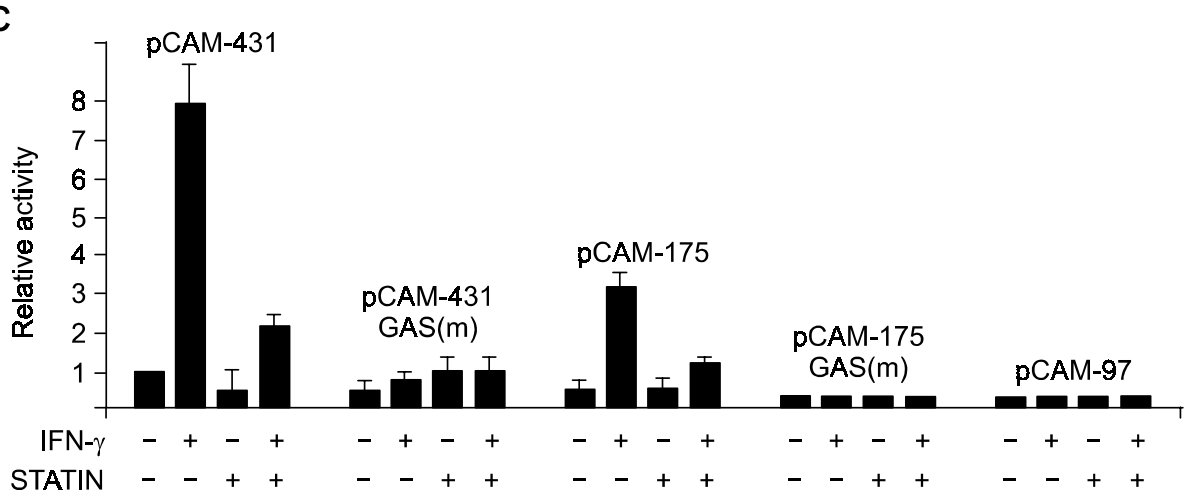

Figure 4. Effect of IFN- $\gamma$, TNF- $\alpha$ and/or statin on the promoter activity of rat ICAM-1 in ECV304 cells. (A) Schematic representation of the ICAM-1 reporter genes used in the experiments. Nucleotide numbering is relative to the translational start site, which is designated +1 (Park et al., 1999). The figure shows the cloned subfragments of the ICAM-1 promoter region located in the upstream of a promoterless firefly luciferase cDNA in pGL2-basic vector (see Materials and Methods). (B) Inhibitory effects of statin on IFN- $\gamma$-induced ICAM-1 promoter activity. The ECV304 cells which stably express pCAM-431 reporter plasmids as indicated were cultured near confluency, then stimulated with IFN- $(10 \mathrm{ng} / \mathrm{ml})$, TNF- $\alpha$ with/without statin pretreatment. All the cell lysates were prepared at the same time and their luciferase assays were performed as described in Materials and Method. (C) The luciferase activity from untreated pCAM-431 was the control for comparison of promoter activities in all other treated cells. The wild type palindromic GAS sequences (5'-TTTCCGGAAA-3') was mutated to a nonpalindromic GAS sequences (5'TTaCCGGtAc-3') in pCAM-431 GAS(m), and pCAM-175 GAS(m) as described in Materials and Methods. All experiments were repeated at least three times. Data were normalized for transfection efficiency and presented as the mean $\pm S E$ of the experiments; significance, $P<0.005$, was determined by 2-way analysis of variance. 
translation (Figure 4C). This region includes two major regulatory elements that mediate IFN- $\gamma$ action in other eukaryotic cells: a GAS sequence at -138 to $-128 \mathrm{bp}$, and an Sp1 sequence at -112 to $-108 \mathrm{bp}$. Mutation of the $11 \mathrm{bp}$ palindromic GAS sequence, pCAM-175 GAS $(m)$ (see Figure 4A) completely eliminated the IFN- $\gamma$-dependent promoter activity of pCAM-175 (Figure $4 \mathrm{C}$ ). Lovastatin inhibits induction of pCAM-175 reporter activity by IFN- $\gamma$.

The GAS element contains a conserved palindromic 11-bp GAS core element, 5'-tttccgggaaa- 3'. The GAS element binds to the STAT family transcription factors STAT1, $-3,-5$ and -6 . In the presence of IFN- $\gamma$, a single STAT1 homodimer binds to the -143 to -119 bp region of the ICAM-1 promoter (Chung et al., 2000).

\section{Effects of lovastatin on IFN- $\gamma$ mediated phosphory- lation of STAT1, ERK1/2 and p38 kinases}

The above results are consistent with the hypothesis that the GAS regulatory sequence in the ICAM-1 promoter may mediate the effect of lovastatin on IFN$\gamma$-induced expression of ICAM-1. Because GAS interacts with IFN- $\gamma / \mathrm{STAT} 1$, the effects of lovastatin on IFN- $\gamma / \mathrm{STAT} 1$ signaling was investigated.

Phosphorylation of STAT1 is regulated by IFN- $\gamma$ and is critical for regulation of STAT1 activity. The single tyrosine residue of STAT1, tyrosine 701, is phosphorylated by JAK1 and JAK2 after stimulation with IFN- $\gamma$. This phosphorylation is essential for the biological activity of STAT1, because only the phosphorylated form of STAT1 dimerizes, and dimerization is required for DNA binding (Darnell et al., 1997). Phosphorylation of serine 727 of STAT1 is also evolutionarily conserved and modulates transcriptional activity of

A
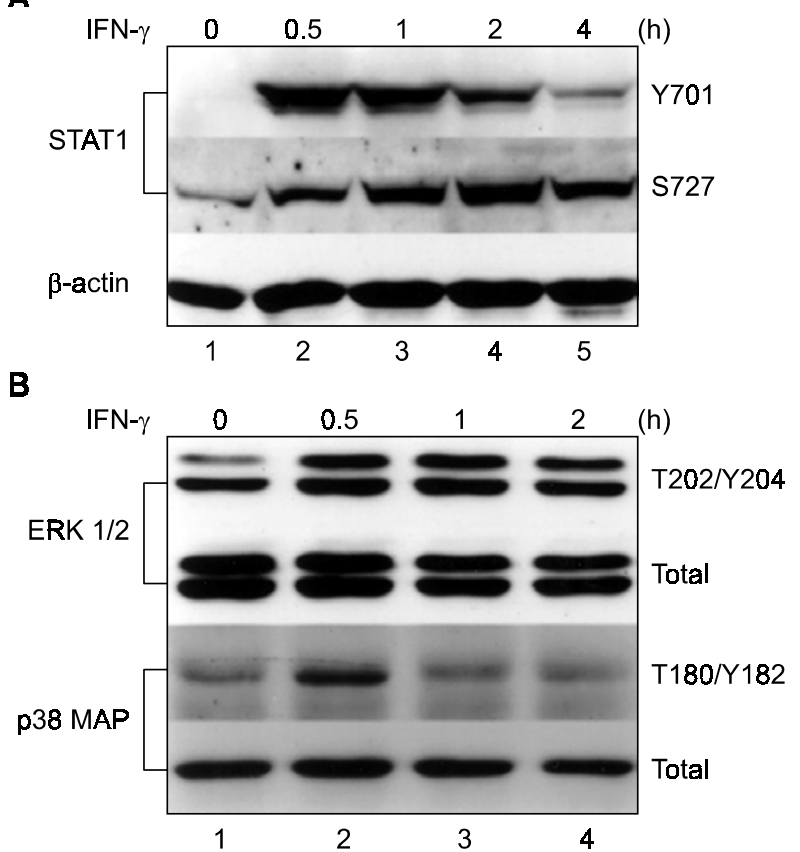

Figure 5. Effect of IFN- $\gamma$ on STAT1, ERK1/2 and p38 activation in ECV304 cells. ECV304 cells were treated with $\mathrm{FN}-\gamma(10 \mathrm{ng} / \mathrm{ml})$ for indicated times. Cell lysates were prepared as described in Materials and Methods. Whole cell lysates were resolved in 10\% SDS-PAGE and further examined for immunoblot analyses with antibodies reacting against phosphorylated and total forms of STAT1, ERK1/2 and p38.
A
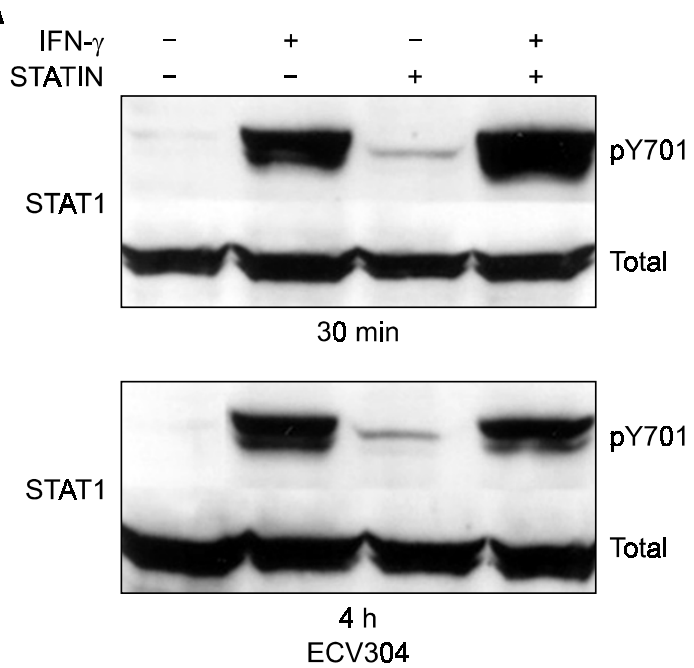
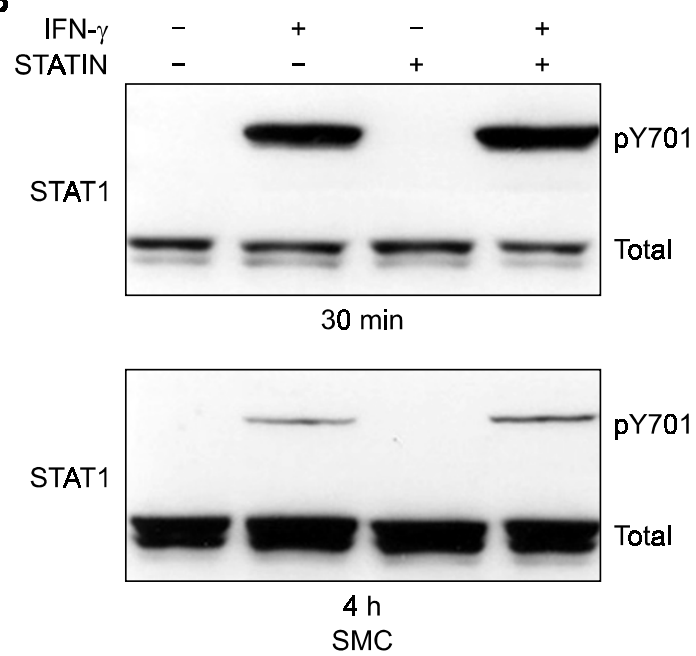

Figure 6. Effects of statin on IFN- - -induced Y701 phosphorylation of STAT1 in ECV304 and SMC. ECV304 and SMC were treated with IFN- $\gamma$ $(10 \mathrm{ng} / \mathrm{ml})$ with/without lovastatin pretreatment. Cell lysates were prepared as described in Materials and Methods. Whole cell lysates were resolved in 10\% SDS-PAGE and further examined for immunoblot analyses with antibodies reacting against phosphorylated and total forms of STAT1. 
STAT1. The kinases that phosphorylate serine 727 are ERK1/ERK2, p38 MAP kinase, JNK and mTOR (Decker et al., 2000).

The phosphorylation state of the tyrosine and serine residues of STAT1 were analyzed in ECV 304 cells treated with or without IFN- $\gamma$ and with or without lovastatin using phosphospecific antibodies. IFN- $\gamma$ rapidly and transiently induced phosphorylation of tyrosine 701 of STAT1, with return to the basal level after $4 \mathrm{~h}$ (Figure 5A, upper). IFN- $\gamma$ also increased phosphorylation of serine 727 within $30 \mathrm{~min}$, and the elevated level persists until $4 \mathrm{~h}$ after IFN- $\gamma$ stimulation.

ERK1/ERK2 and p38 MAP kinase are responsible for serine 727 phosphorylation of STAT1. The phosphorylation state of these enzymes was analyzed using phosphospecific antibodies for threonine 202/tyrosine 204 phosphorylated forms of ERK1 and ERK2 (Figure 5B). The level of phosphorylated ERK1/ERK2 increased rapidly within $30 \mathrm{~min}$ in the presence of IFN- $\gamma$ (Figure 5B, lane 1 vs. lane 2).

p38 MAP kinase, also called RK and CSBP, is activated by MKK3 and SEK, which phosphorylates the enzyme at threonine 180 and tyrosine 182. Activated p38 MAP kinase phosphorylates serine 727 residue of STAT1 (Wertheimer et al., 1992). In ECV 304 cells treated with IFN- $\gamma$, there is a rapid increase in phosphorylation of threonine 180/tyrosine 182 in p38 MAP kinase (Figure 5B).

The effects of lovastatin on tyrosine 701 and serine 727 phosphorylation of STAT1 were also examined in ECV 304 and vascular SMC. IFN- $\gamma$ induced rapid but persistent induction of the tyrosine 701 phosphorylated form of STAT1 (Figure 6A and B). Lovastatin did not inhibit or stimulate the IFN- $\gamma$-dependent increase in the tyrosine 701 phosphorylated form of STAT1 in ECV 304 and SMC. These findings suggest that atoravastatin does not affect the IFN- $\gamma$-mediated JAKISTAT1 (tyrosine 701 phosphorylation) signaling pathway.

However, lovastatin did have an effect on serine 727 phosphorylation of STAT1 and threonine 202/ tyrosine 204 phosphorylation of ERK1/ERK2 in cells treated wtih IFN- $\gamma$ (Figure 7). IFN- $\gamma$ upregulated phosphorylation of threonine 202 and tyrosine 204 of
A

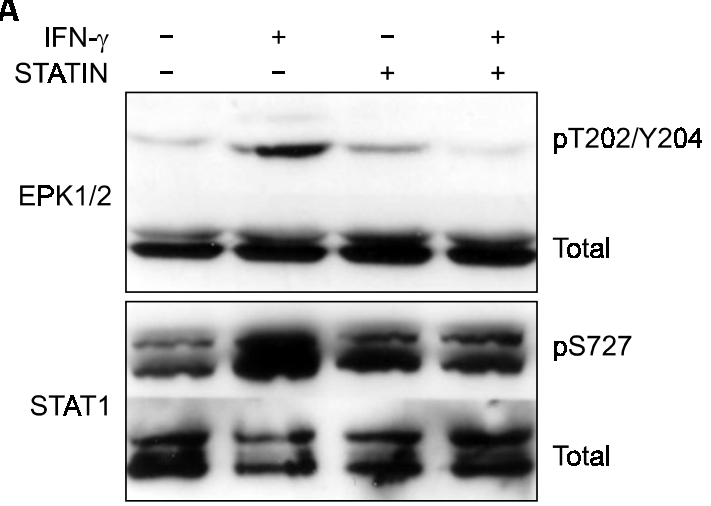

B

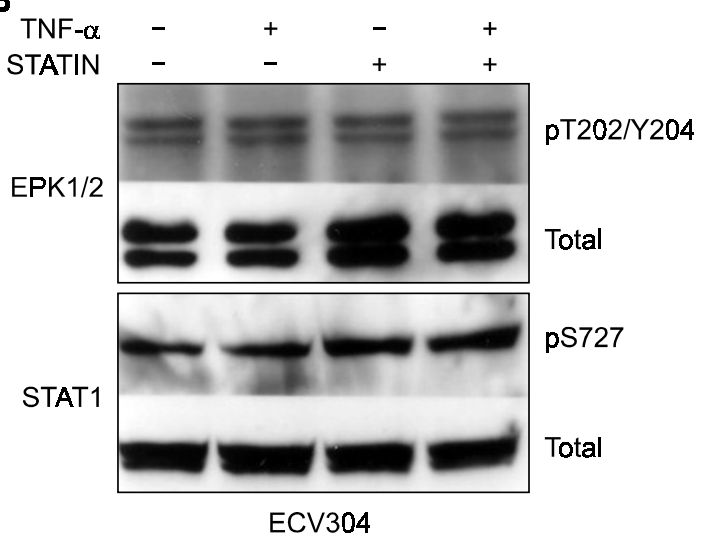

C

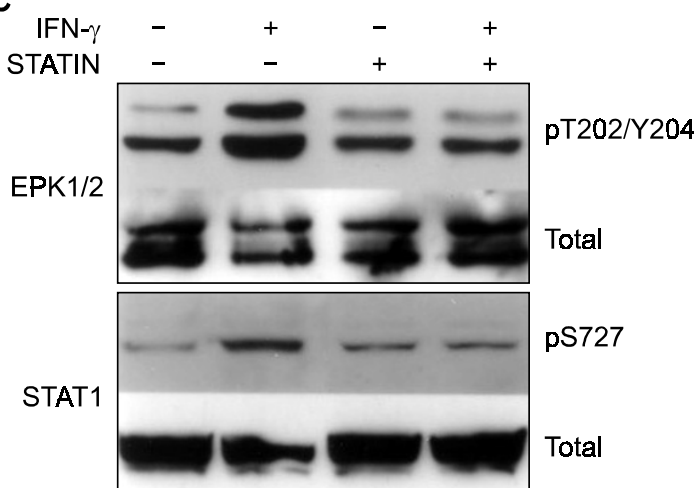

D

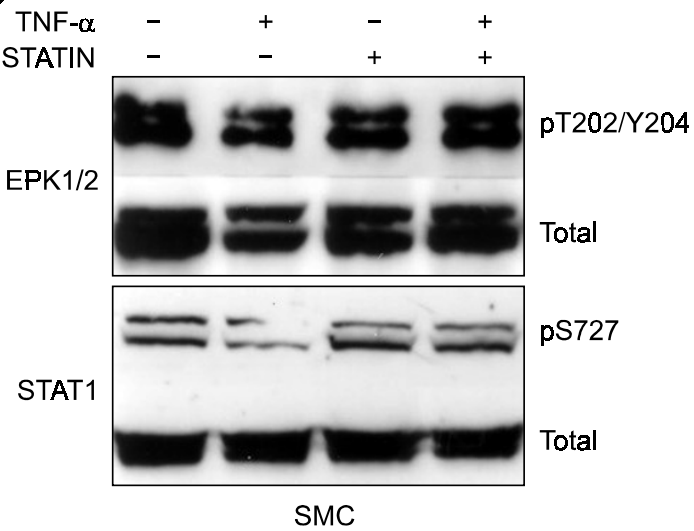

Figure 7. Effects of statin on IFN- - -induced T202/Y204 phosphorylation of ERK1/2 and S727 phosphorylation of STAT1 in ECV304 and SMC. ECV304 and SMC were treated with IFN- $\gamma(10 \mathrm{ng} / \mathrm{ml})$ and TNF- $\alpha$ with/without lovastatin pretreatment. Cell lysates were prepared as described in Materials and Methods. Whole cell lysates were resolved in 10\% SDS-PAGE and further examined for immunoblot analyses with antibodies reacting against phosphorylated and total forms of STAT1, ERK1/2. 
ERK1/ERK2 and serine 727 of STAT1 (Figure 7A and C). However, lovastatin inhibits this effect, such that these phosphorylated forms of ERK1/ERK2 and STAT1 are not increased. In addition, TNF- $\alpha$ did not affect the phosphorylation state of threonine 202/tyrosine 204 of ERK1/ERK2 and serine 727 in ECV304 and smooth muscle cells, and lovastatin did not change the basal level of phosphorylation of ERK1/ERK2 and serine 727 STAT1 (Figure 7B and D). These findings suggest that lovastatin inhibits IFN- $\gamma$-dependent induction of ICAM-1 expression by suppressing the ERKSTAT serine 727 activation pathway.

\section{Discussion}

This study shows that lovastatin, an inhibitor of HMGCoA reductase, inhibits IFN- $\gamma$-dependent induction of ICAM-1 by suppressing phosphorylation of ERK1/ ERK2 and serine727 phosphorylation of STAT1. In contrast, lovastatin has no effect on TNF- $\alpha$ mediated induction of ICAM-1.

In endothelial cells, expression of ICAM-1 requires de novo mRNA expression and protein synthesis (Dustin et al., 1986; Wertheimer et al., 1992). IFN- $\gamma$ and TNF- $\alpha$ induce a high level of expression of ICAM1 by a mechanism involving transcriptional activation (Rothlein et al., 1988; Look et al., 1994). INF- $\gamma$ mediated induction of ICAM-1 requires a GAS that is at position -116 to $-106 \mathrm{bp}$ in the ICAM-1 promoter region (Dwight et al., 1995). An ICAM-1 promoter with a mutation in the palindromic GAS does not respond to IFN- $\gamma$ (Dwight et al., 1995). The downstream GCbox at 99 to $-94 \mathrm{bp}$ in the human ICAM-1 promoter binds to Sp1, and this Sp1 binding element is also critical for STAT1-dependent expression of ICAM-1. This suggests that STAT1 and Sp1 act synergistically in regulating expression of ICAM-1 (Dwight et al., 1995).

The GAS in the rat ICAM-1 promoter is similar to the GAS in the human ICAM-1 promoter, and the functional role of GAS and Sp1 in response to IFN- $\gamma$ is similar in both species (Park et al., 1999). The GAS from the ICAM-1 promoter also binds a STAT1 homodimer in the presence of IFN- $\gamma$. The STAT1/DNA complex induced by IFN- $\gamma$ is regulated by JAK1/JAK2dependent phosphorylation of tyrosine 701 of STAT1. Lovastatin does not affect IFN- $\gamma$-dependent phosphorylation of STAT1 tyrosine 701. This finding suggests that lovastatin may not interact with the IFN- $\gamma$ receptor-mediated JAK/STAT1 tyrosine phosphorylation pathway.

STAT1 has a motif near its C-terminus, $P(M) S$ (727) $\mathrm{P}$, that is a potential serine phosphorylation site for proline-directed kinases such as MAP family kinases (Zhu et al., 1997). Phosphorylation of STAT1 serine 727 plays a role in activation of transcription and DNA binding (Wen et al., 1995; Zhang et al., 1995). MAP kinases (ERK1/2) (David et al., 1995), p38 MAP kinase (Goh et al., 1999), protein kinase $\mathrm{C}-\delta$ (PKC $\delta$ ) (Jain et al., 1999), and mTOR kinase (Yokogami et al., 2000) are involved in phosphorylation of STAT1 and/or STAT3 serine 727. This study shows that IFN- $y$ triggers phosphorylation of threonine 202/tyrosine 204 of ERK1/2 and of threonine180/ tyrosine182 of p38 MAP kinase. Interestingly, IFN- $\gamma$ induced phosphorylation of threonine 202tyrosine 204 of ERK $1 / 2$ is inhibited by lovastatin and furthermore, IFN- $\gamma$-induced phosphorylation of serine 727 of STAT1 is also reduced by lovastatin. These findings suggest that lovastatin inhibits the IFN- $\gamma$-mediated ERK/STAT1 signaling pathway.

It has been reported that IFN- $\gamma$ activates raf-1, an upstream kinase for the MEK/ERK signaling pathway. Xia et al. (Xia et al., 1996) showed that in IFN- $\gamma$ treated cells, JAK2 activates raf-1 and the activation requires the presence of $\mathrm{p} 21^{\text {ras}}$; however, Sakatsume et al. (Sakatsume et al., 1998) observed that raf-1 is activated by a JAK1-dependent $\mathrm{p} 21^{\text {ras }}$-independent pathway in IFN- $\gamma$ treated cells. This study does not address the mechanism by which IFN- $\gamma$-activates raf/MEKJERK in endothelial cells and SMC. In addition, the role of $\mathrm{p} 21^{\text {ras }}$ in INF- $\gamma$-induced activation of ERK1/2 is still obscure. Inhibitors of HMG-CoA reductase block post-translational modifications of proteins including the farnesylation and geranylgeranylation of $\mathrm{p} 21^{\text {ras }}$ (Jakobisiak et al., 1991). This study shows that lovastatin inhibits IFN- $\gamma$-induced phosphorylation of ERK1/2 and STAT1 serine 727. There are several possibilities for the mechanism by which lovastatin inhibits activation of ERK/STAT1; these include 1) inhibition of $p 21^{\text {ras }}$ modification and subsequent suppression of ras-dependent activation of raf-1; and 2) inhibition of JAK1 and/or JAK2 activities or their association with raf-1. The IFN- $\gamma$ activated JAK1 and JAK2 pathway is inhibited by SOCS/SSI/ JAB family proteins (Starr et al., 1997) but lovastatin did not induce SOCS-1 or SOCS-3 (data not shown). Therefore, inhibition of IFN- $\gamma$-induced JAK1/JAK2 activation may not result from induction of SOCS.

While this paper was in preparation, Sadeghi et al., (Sadeghi et al., 2000) reported that the HMG-CoA reductase inhibitor simvastatin potentiates $\mathrm{IL}-1$ and TNF- $\alpha$-induced expression of ICAM-1, E-selectin, and VCAM-1 in HUVEC cells. They postulated that the increased expression of these cell adhesion molecules is due to increased translocation of NF-kB. In addition, they showed that pertussis toxin mimics the effect of simvastatin, indicating that $\mathrm{G}_{\mathrm{ia}}$ may be involved simvastatin's effects on gene expression. Thus, the results of Sadeghi et al. contradict the results reported here, because lovastatin had no effect on 
TNF- $\alpha$-dependent induction of ICAM-1. The reason for this discrepancy is not clear at present. Several different cytokines and several different cell types (i.e., endothelial, SMC and immune cells) contribute to the atherosclerotic process in vivo. Therefore, it is possible that different statins have different effects, or that their effects vary according to cell type. This possibility should be tested in future experiments.

In summary, this study demonstrates that lovastatin inhibits the ability of IFN- $\gamma$ to induce ICAM-1 in endothelial and vascular SMC. IFN- $\gamma$ is a major cytokine involved in the immunological pathogenesis of atherosclerosis. Thus, this finding suggests that statins may be useful as therapeutic agents for atherosclerosis, because they inhibit the action of IFN- $\gamma$ and they lower serum lipids.

\section{Acknowledgements}

This work was supported by National Research Laboratory Program (M1-0104-00-0014), Ministry of Science and Technology, Korea and Pfizer Korea Research Grant, Korea. We thank Dr T. A. Springer for the gift of human ICAM-1 vector and helpful suggestions.

\section{References}

An BS, Ku BJ, Park SY, Shin JK, Lee JH, Kim YK, Shong $\mathrm{MH}$, Ro HK. Hormonal regulation of ICAM-1 gene expression in thyroid cells, FRTL-5. Exp Mol Med 1997;29:45-51

Chung J, Park ES, Kim D, Suh JM, Chung HK, Kim J, Kim H, Park SJ, Kwon OY, Ro HK, Shong M. Thyrotropin modulates interferon-gamma-mediated intercellular adhesion molecule-1 gene expression by inhibiting Janus kinase- 1 and signal transducer and activator of transcription-1 activation in thyroid cells. Endocrinology 2000;141:2090-7

Collins RG, Velji R, Guevara NV, Hicks MJ, Chan L, Beaudet AL. P-Selectin or intercellular adhesion molecule (ICAM)-1 deficiency substantially protects against atherosclerosis in apolipoprotein E-deficient mice. J Exp Med 2000;191:189-94

Darnell JE Jr: STATs and gene regulation. Science 1997; 277:1630-5

David M, Petricoin E 3rd, Benjamin C, Pine R, Weber MJ, Larner AC. Requirement for MAP kinase (ERK2) activity in interferon alpha- and interferon beta-stimulated gene expression through STAT proteins. Science 1995;269:1721-3

Decker T, Kovarik P. Serine phosphorylation of STATs. Oncogene 2000;19:2628-37

Dustin ML, Rothlein R, Bhan AK, Dinarello CA, Springer TA. Induction by IL 1 and interferon-gamma: tissue distribution, biochemistry, and function of a natural adherence molecule (ICAM-1). J Immunol 1986;137:245-54

Dwight C. Look, Mark R. Pelletier, Rose M. Tidwell, William
T. Roswit, Michael J. Holtzman. Stat1 Depends on Transcriptional Synergy with Sp1 J Biol Chem 1995;270: 30264-7

Goh KC, Haque SJ, Williams BR. p38 MAP kinase is required for STAT1 serine phosphorylation and transcriptional activation induced by interferons. EMBO J 1999;18:5601-8

Gotto AM Jr: Statin therapy: where are we? Where do we go next? Am J Cardiol 2001;87:13B-8B

Guijarro C, Blanco-Colio LM, Ortego M, Alonso C, Ortiz A, Plaza JJ, Diaz C, Hernandez G, Edigo J. 3-Hydroxy-3methylglutaryl coenzyme a reductase and isoprenylation inhibitors induce apoptosis of vascular smooth muscle cells in culture. Circ Res 1998;83:490-500

Gupta S, Pablo AM, Jiang Xc, Wang N, Tall AR, Schindler C. IFN-gamma potentiates atherosclerosis in ApoE knock-out mice. J Clin Invest 1997;99:2752-61

Jakobisiak M, Bruno S, Skierski JS, Darzynkiewicz Z. Cell cycle-specific effects of lovastatin. Proc Natl Acad Sci USA 1991;88:3628-32

Jain N, Zhang T, Kee WH, Li W, Cao X. Protein kinase $C$ delta associates with and phosphorylates Stat3 in an interleukin-6-dependent manner. J Biol Chem 1999;274: 24392-400

Kim JS, Pirnia F, Choi YH, Nguyen PM, Knepper B, Tsokos M, Schulte TW, Birrer MJ, Blagosklonny MV, Schaefer O, Mushinski JF, Trepel JB. Lovastatin induces apoptosis in a primitive neuroectodermal tumor cell line in association with RB down-regulation and loss of the G1 checkpoint. Oncogene 2000,19:6082-90

Kureishi Y, Luo Z, Shiojima I, Bialik A, Fulton D, Lefer DJ, Sessa WC, Walsh K. The HMG-CoA reductase inhibitor simvastatin activates the protein kinase Akt and promotes angiogenesis in normocholesterolemic animals. Nat Med 2000; 6:1004-10

Kwak B, Mulhaupt F, Myit S, Mach F. Statins as a newly recognized type of immunomodulator. Nat Med 2000;6:1399402

Laufs U, Liao JK. Direct vascular effects of HMG-CoA reductase inhibitors. Trends Cardiovasc Med 2000;10:143-8

Look DC, Pelletier MR, Holtzman MJ. Selective interaction of a subset of interferon-gamma response element-binding proteins with the intercellular adhesion molecule-1 (ICAM-1) gene promoter controls the pattern of expression on epithelial cells. J Biol Chem 1994;269:8952-8

Naderi S, Blomhoff R, Myklebust J, Smeland EB, Erikstein $B$, Norum KR, Blomhoff HK. Lovastatin inhibits G1/S transition of normal human B-lymphocytes independent of apoptosis. Exp Cell Res 1999;252:144-53

Nagano H, Mitchell RN, Taylor MK, Hasegawa S, Tilney NL, Libby $\mathrm{P}$. Interferon-gamma deficiency prevents coronary arteriosclerosis but not myocardial rejection in transplanted mouse hearts. J Clin Invest 1997;100:550-7

Maron DJ, Fazio S, Linton MF. Current perspectives on statins. Circulation 2000;101:207-13

Park ES, You SH, Kim H, Kwon OY, Ro HK, Cho BY, Taniguchi SI, Kohn LD, Shong M: Hormone-dependent regulation of intercellular adhesion molecule-1 gene expres- 
sion: cloning and analysis of 5 '-regulatory region of rat intercellular adhesion molecule-1 gene in FRTL-5 rat thyroid cells. Thyroid 1999;9:601-12

Pedersen TR. Statin trials and goals of cholesterol-lowering therapy after AMI. Am Heart J 1999;138(2 Pt 2):S177-82

Ross R. The pathogenesis of atherosclerosis: a perspective for the 1990s. Nature 1993;362:801-9

Rothlein R, Czajkowski M, O'Neill MM, Marlin SD, Mainolfi $\mathrm{E}$, Merluzzi VJ. Induction of intercellular adhesion molecule 1 on primary and continuous cell lines by pro-inflammatory cytokines. Regulation by pharmacologic agents and neutralizing antibodies. J Immunol 1988;141:1665-9

Sadeghi MM, Collinge M, Pardi R, Bender JR. Simvastatin modulates cytokine-mediated endothelial cell adhesion molecule induction: involvement of an inhibitory $G$ protein. J Immunol 2000;165:2712-8

Sakatsume $M$, Stancato $L F$, David $M$, Silvennoinen $O$, Saharinen P, Pierce J, Larner AC, Finbloom DS. Interferon gamma activation of Raf-1 is Jak1-dependent and p21rasindependent. J Biol Chem 1998;273:3021-6

Starr R, Willson TA, Viney EM, Murray LJ, Rayner JR, Jenkins BJ, Gonda TJ, Alexander WS, Metcalf D, Nicola NA, Hilton DJ. A family of cytokine-inducible inhibitors of signalling. Nature 1997;387:917-21

Stratowa C, Audette M. Transcriptional regulation of the human intercellular adhesion molecule-1 gene: a short overview. Immunobiology 1995;193:293-304

Takai Y, Sasaki T, Matozaki T. Small GTP-binding proteins. Physiol Rev 2001;81:153-208
Walter MJ, Look DC, Tidwell RM, Roswit WT, Holtzman MJ: Targeted inhibition of interferon-gamma-dependent intercellular adhesion molecule-1 (ICAM-1) expression using dominant-negative Stat1. J Biol Chem 1997;272:28582-9

Wen Z, Zhong Z, Darnell JE Jr. Maximal activation of transcription by Stat 1 and Stat 3 requires both tyrosine and serine phosphorylation. Cell 1995;82:241-50

Wertheimer SJ, Myers CL, Wallace RW, Parks TP. Intercellular adhesion molecule-1 gene expression in human endothelial cells. Differential regulation by tumor necrosis factor-alpha and phorbol myristate acetate. J Biol Chem 1992;267:12030-5

Xia K, Mukhopadhyay NK, Inhorn RC, Barber DL, Rose PE, Lee RS, Narsimhan RP, D'Andrea AD, Griffin JD, Roberts TM. The cytokine-activated tyrosine kinase JAK2 activates Raf-1 in a p21ras-dependent manner. Proc Natl Acad Sci USA 1996;93:11681-6

Yokogami K, Wakisaka S, Avruch J, Reeves SA. Serine phosphorylation and maximal activation of STAT3 during CNTF signaling is mediated by the rapamycin target mTOR. Curr Biol 2000;10:47-50

Zhang X, Blenis J, Li HC, Schindler C, Chen-Kiang S. Requirement of serine phosphorylation for formation of STATpromoter complexes. Science 1995;267:1990-4

Zhu X, Wen Z, Xu LZ, Darnell JE Jr: Stat1 serine phosphorylation occurs independently of tyrosine phosphorylation and requires an activated Jak2 kinasem Mol Cell Biol $1997 ; 17: 6618-23$ 